\title{
Emulsification in Batch-Emulsion Polymerization of Styrene and Vinyl Acetate: A Reaction Calorimetric Study
}

\author{
M. F. KEMMERE, J. MEULDIJK, A. A. H. DRINKENBURG, A. L. GERMAN \\ Process Development Group, Department of Chemical Engineering, Eindhoven University of Technology, P.O. Box 513, \\ 5600 MB Eindhoven, The Netherlands
}

Received 2 December 1999; accepted 20 May 2000

\begin{abstract}
Dispersion of liquid-liquid systems is commonly applied in industrial processes such as extraction, suspension, and emulsion polymerization. This article describes the influence of the quality of emulsification on the course and outcome of a batch-emulsion polymerization of styrene and vinyl acetate. From visualization experiments and polymerizations in combination with reaction calorimetric studies, a critical impeller speed, $N^{*}$, can accurately be determined for a particular reactor setup and a given recipe. The results show that styrene-water emulsions are more difficult to emulsify than vinyl acetate-water emulsions. In general, a large turbine impeller appears to be more effective in emulsifying monomer-water dispersions than a pitchedblade impeller. In addition, for vinyl acetate emulsion polymerization, the possibility of premixing the reaction mixture has been investigated. (C) 2000 John Wiley \& Sons, Inc. J Appl Polym Sci 79: 944-957, 2001
\end{abstract}

Key words: emulsification; emulsion polymerization; styrene; vinyl acetate; reaction calorimetry

\section{INTRODUCTION}

Emulsion polymerization is a free radical polymerization in a heterogeneous reaction system. At the beginning of a batch-emulsion polymerization, the monomer is present mainly in droplets being dispersed in the continuous aqueous phase. During the reaction stirring is required to keep the monomer properly dispersed. Insufficient emulsification results in mass transfer limitation of the monomer from the monomer phase to the growing polymer particles. This article combines the general understanding of emulsification with the specific characteristics of the emulsion polymerization. The impact of emulsification during

Correspondence to: M. F. Kemmere (m.f.kemmere@tue.nl). Journal of Applied Polymer Science, Vol. 79, 944-957 (2001) (ㄷ) 2000 John Wiley \& Sons, Inc. emulsion polymerization of styrene was already reported in a previous article. ${ }^{1}$ The influence of dispersion of the monomer in the continuous aqueous phase on the course and outcome of the batch-emulsion polymerization process has been studied. For this purpose a criterion developed by visualization experiments has been applied for determining an impeller speed $\left(N_{\mathrm{vis}}^{*}\right)$ just sufficient to completely disperse the monomer phase into the aqueous phase. In polymerization experiments at the same conditions, $N_{\text {vis }}^{*}$ appears to be the critical value above which no further increase in the polymerization rate is observed $\left(N_{\text {pol }}^{*}\right)$. In the present article emulsification effects during emulsion polymerization of vinyl acetate have been investigated. In addition, reaction calorimetry has been applied to study the effect of emulsification on the rate of heat production during the emulsion polymerization of styrene and vinyl acetate. 


\section{Emulsification in Emulsion Polymerization of Vinyl Acetate}

Some general background information on emulsification in emulsion polymerization was already been given in our previous article. ${ }^{1}$ Emulsification is the process of making an emulsion from a system consisting of two more or less immiscible liquids. ${ }^{2}$ To facilitate emulsification, a surfactant is added in many cases. The droplet size distribution is governed by a dynamic equilibrium between breakup and coalescence of the droplets. The required energy is supplied by the stirrer. Emulsification is influenced by the equipment and the energy dissipated into the liquid mixture due to stirring as well as by the physicochemical properties of the system. The distribution of the power transferred into the liquid mixture by the impeller depends on the geometrical arrangement, that is, the reactor dimensions and the position, type, and diameter of the impeller. The physicochemical properties of the mixture, that is, density and viscosity of the liquids involved and surface tension between the two phases, affect the emulsification process as well as the course and outcome of the emulsion polymerization itself. Fontenot and Schork ${ }^{3}$ observed that less-water-soluble monomers such as styrene are more difficult to emulsify as compared to monomers such as vinyl acetate, which are more water soluble. For intrinsic polymerization the dependence of the course of the process on the concentrations of the emulsifier and the initiator in the recipe is significantly different for styrene and vinyl acetate. Styrene and vinyl acetate obey case $2^{4}$ and case 1 kinetics, ${ }^{5}$ respectively. For styrene micellar nucleation is dominant, while for vinyl acetate homogeneous nucleation plays an important role. For the conversion region, where the rate of polymerization ( $R p)$ of vinyl acetate does not depend on conversion, the following expression has been reported in literature, ${ }^{7,8}$ based on the article by Ugelstad et al. ${ }^{6}$

$$
R_{p} \propto C_{I, 0}^{0.5} C_{E, 0}^{0}
$$

\section{EXPERIMENTAL}

Three types of experiments were carried out to gain insight into the influence of emulsification on the emulsion polymerization process. In addition to the visualization experiments, emulsion polymerizations were performed in common stirred- tank reactors and in a reaction calorimeter-both done in order to study emulsification under reaction conditions.

\section{Visualization Experiments for Studying Emulsification}

The influences of emulsifier concentration, monomer-to-water ratio, temperature, and mixing conditions on the emulsification of vinyl acetate and styrene emulsion systems were studied in glass vessels with the same geometry as the polymerization reactors. A criterion based on visual observation was used to determine the lowest impeller speed for sufficient emulsification $\left(N_{\mathrm{vis}}^{*}\right)$. Our previous article reported on this experimental procedure in detail. ${ }^{1}$

\section{Emulsion Polymerizations in Common Stirred-Tank Reactors}

In order to apply the concept of $N_{\mathrm{vis}}^{*}$ to reacting emulsion systems, polymerization experiments were carried out to determine the lowest impeller speed $\left(N_{\text {pol }}^{*}\right)$ that would allow polymerization at the highest rate, that is, intrinsic polymerization. The question is whether $N_{\mathrm{pol}}^{*}$ equals $N_{\mathrm{vis}}^{*}$, as determined from visualization experiments without reaction.

The batch-emulsion homopolymerization of styrene and vinyl acetate was performed in stainless-steel stirred-tank reactors of different scales (1.85 and $7.48 \mathrm{dm}^{3}$, respectively) equipped with four baffles and with external jackets for heating and cooling. For all experiments the liquid height was taken equal to the vessel diameter. Rushton six-bladed turbine impellers as well as downflow $45^{\circ}$ pitched six-bladed impellers of a third and a half the vessel diameter, respectively, were used. The clearance of the impeller from the bottom was always taken at half the vessel diameter. In addition, emulsion polymerization experiments

Table I Dimensions (mm) of the Polymerization Reactors Used

\begin{tabular}{lrrc}
\hline \multicolumn{1}{c}{ Scale $\left[\mathrm{dm}^{3}\right]$} & 1.85 & 7.48 & $0.833(\mathrm{RC} 1 \mathrm{e})$ \\
\hline Internal diameter, $D$ & 133 & 212 & 102 \\
Liquid height, $H_{\text {fill }}$ & 133 & 212 & 102 \\
Clearance of impeller, $C$ & 66 & 106 & 51 \\
Diameter baffles, $d_{b}$ & 13 & 20 & - \\
Thickness baffles, $t_{b}$ & 1.5 & 2 & - \\
\hline
\end{tabular}


Table II Dimensions (mm) of the Rushton Turbine Impellers

\begin{tabular}{|c|c|c|c|c|c|c|}
\hline \multirow{2}{*}{$\begin{array}{l}\text { Scale }\left[\mathrm{dm}^{3}\right] \\
\text { D/d Ratio }\end{array}$} & \multicolumn{2}{|c|}{1.85} & \multicolumn{2}{|c|}{7.48} & \multicolumn{2}{|c|}{$0.833(\mathrm{RC} 1 \mathrm{e})$} \\
\hline & 3 & 2 & 3 & 2 & 3 & 2 \\
\hline Impeller diameter, $d$ & 44 & 66 & 71 & 106 & 34 & 51 \\
\hline Blade width, $w$ & 9 & 13 & 14 & 21 & 7 & 10 \\
\hline Blade length, $l$ & 11 & 16 & 18 & 26 & 9 & 13 \\
\hline Blade thickness & 1.5 & 1.5 & 1.5 & 1.5 & 1 & 1 \\
\hline Disk diameter & 33 & 50 & 53 & 79 & 26 & 38 \\
\hline Disk thickness & 1.5 & 1.5 & 1.5 & 1.5 & 1 & 1 \\
\hline Shaft diameter & 7 & 7 & 10 & 10 & 10 & 10 \\
\hline Shaft holder diameter & 12 & 12 & 18 & 27 & 12 & 15 \\
\hline Power number, $N_{p}[-]$ & 5.2 & 4.9 & 4.4 & 4.4 & $5.0^{9}$ & $5.0^{9}$ \\
\hline
\end{tabular}

For symbols, see Figure 1.

were performed in a reaction calorimeter $(\mathrm{RC} 1 \mathrm{e})$ with a slightly different reactor geometry. Tables I-III summarize the dimensions of the equipment. Figure 1 shows a schematic view of the reactor configuration as well as the impellers used in this study. The power number, $N_{p}$, for each impeller-tank combination was determined from the torque exerted on the impeller shaft, except for the $\mathrm{RC} 1 \mathrm{e}$ reactor. In this case the power number was adopted from the literature because an accurate torque meter was lacking. Torque measurements were carried out in glycerol-water mixtures. Although in principle the power number is a function of the Reynolds number, ${ }^{11}$ variations in the power number with Reynolds during the polymerization experiments have been shown to be rather limited. Therefore, the power number was assumed to be constant during all experiments.

The power $(P)$ transferred into the liquid mixture due to stirring can be determined from the torque on the impeller shaft, or it can be estimated using the dimensionless power number $N_{p}$ :

$$
\begin{gathered}
P=2 \pi N_{i} T_{q} \\
P=N_{p} \rho_{M} N_{i}^{3} d^{5}
\end{gathered}
$$

where $N_{i}$ is the impeller speed, $T_{q}$ is the torque, $\rho_{M}$ is the density of the mixture, and $d$ is the impeller diameter.

The mean energy dissipation, $\epsilon_{a v}$-the power input per unit of mass - is given by

$$
\varepsilon_{a v}=\frac{P}{M_{r m}}
$$

where $M_{r m}$ is the mass of the mixture.

The chemicals used in this study were distilled water, commercial-grade styrene, and vinyl ace-

\begin{tabular}{|c|c|c|c|c|c|c|}
\hline \multirow{2}{*}{$\begin{array}{l}\text { Scale }\left[\mathrm{dm}^{3}\right] \\
D / d \text { ratio }\end{array}$} & \multicolumn{2}{|c|}{1.85} & \multicolumn{2}{|c|}{7.48} & \multicolumn{2}{|c|}{$0.833(\mathrm{RC} 1 \mathrm{e})$} \\
\hline & 3 & 2 & 3 & 2 & 3 & 2 \\
\hline Impeller diameter, $d$ & 44 & 66 & 71 & 106 & 34 & 51 \\
\hline Blade width, $w$ & 9 & 13 & 14 & 21 & 7 & 10 \\
\hline Blade length, $l$ & 16 & 26 & 26 & 40 & 11 & 18 \\
\hline Blade thickness & 1.5 & 1.5 & 1.5 & 1.5 & 1 & 1 \\
\hline Shaft diameter & 7 & 7 & 10 & 10 & 10 & 10 \\
\hline Shaft holder diameter & 12 & 12 & 18 & 27 & 12 & 15 \\
\hline Power number, $N_{p}[-]$ & 2.6 & 2.1 & 1.6 & 1.3 & $1.4^{11}$ & $1.4^{11}$ \\
\hline
\end{tabular}
tate, all supplied by DSM; and sodium dodecyl

Table III Dimensions ( $\mathrm{mm}$ ) of the $45^{\circ}$ Pitched Downflow Six-Bladed Impellers

For Symbols, see Figure 1. 

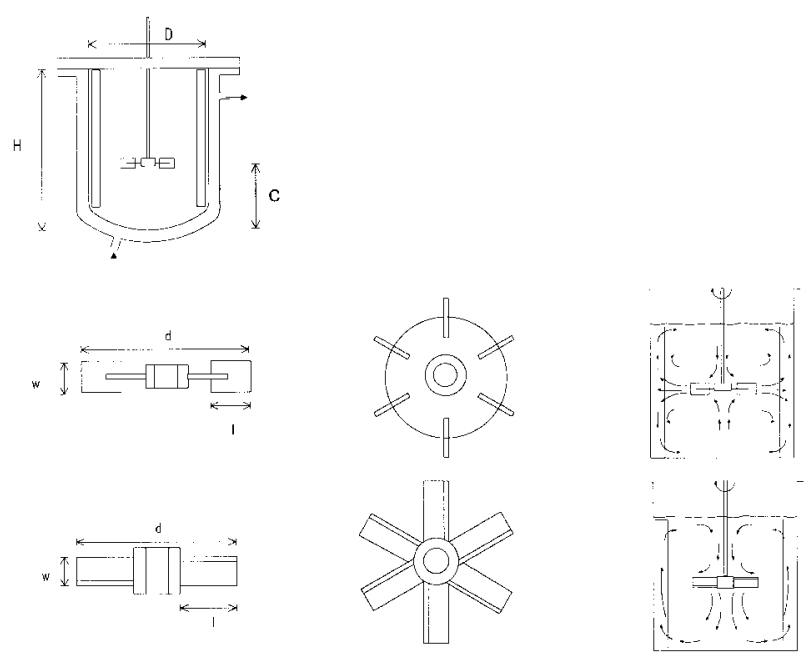

Figure 1 Schematic view of polymerization reactors, turbine, and $45^{\circ}$ pitched six-bladed impellers with corresponding flow pattern.

sulfate (emulsifier), sodium persulfate (initiator), sodium carbonate ( $\mathrm{pH}$ buffer), and sodium chloride (electrolyte), all laboratory grade and all supplied by Merck. Before usage the monomers were distilled under reduced pressure to remove the inhibitor 4-tert-butylcatechol (TBC). Note that traces of TBC influence the course and outcome of the emulsion polymerization process. ${ }^{12}$ The reaction temperature was $50^{\circ} \mathrm{C}$. The recipe used for the $a b$ initio emulsion polymerization experiments and the reaction calorimetric studies is given in Table IV. Prior to use, the water and monomer were flushed with argon separately to remove oxygen. The emulsifier and buffer were dissolved in distilled water. The reactor was charged with both the aqueous and monomer phases. Subsequently, the reaction mixture was stirred under an argon atmosphere and heated until the reaction temperature was reached. Finally, the reaction was started by adding the aqueous initiator solution. During polymerization, samples were taken to determine the con-

Table IV Recipe Used for the Ab-Initio Emulsion Polymerization Experiments of Styrene and Vinyl Acetate

\begin{tabular}{cl}
\hline$M[-]$ & \multicolumn{1}{c}{0.25} \\
\hline$C_{E}\left[\mathrm{kmol} / m_{w}^{3}\right]$ & $0.010 / 0.020$ \\
$C_{I}\left[\mathrm{kmol} / m_{w}^{3}\right]$ & 0.010 \\
$C_{B}\left[\mathrm{kmol} / m_{w}^{3}\right]$ & 0.0090 \\
\hline
\end{tabular}
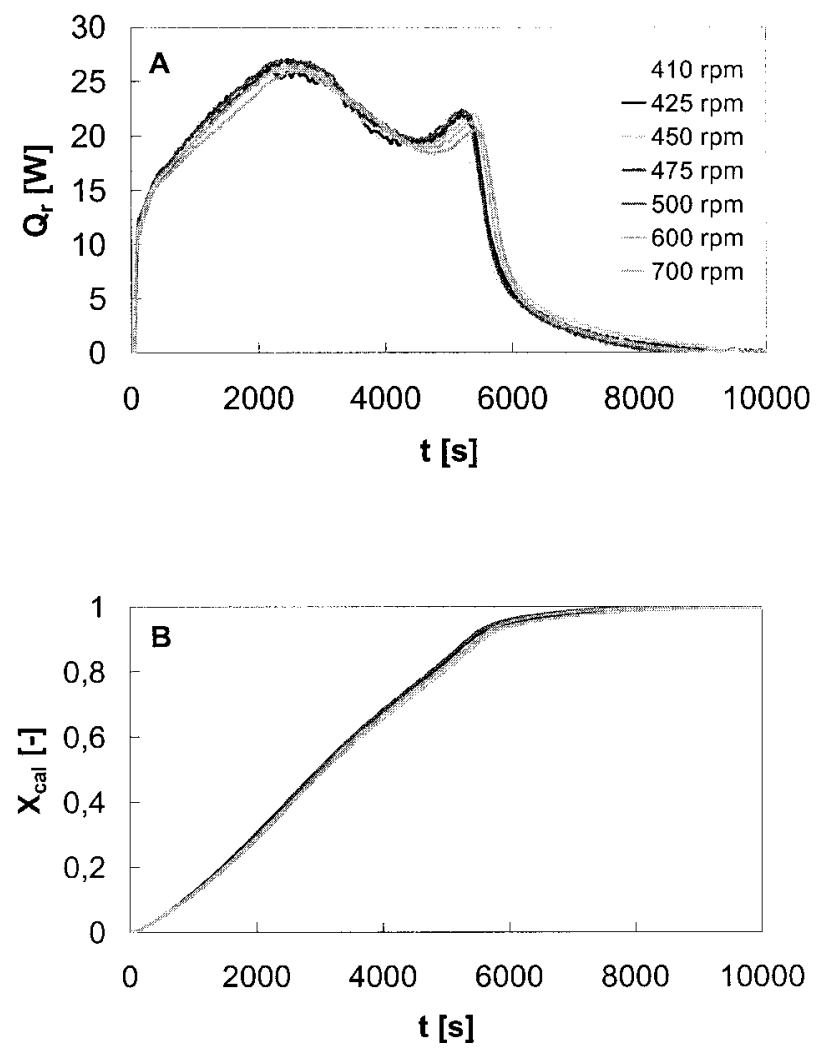

Figure 2 Reaction calorimetric study of the emulsion polymerization of styrene with a turbine impeller $1 / 3 D$ in diameter: (A) Rate of heat production by polymerization as a function of time; (B) Fractional reaction calorimetric conversion as a function of time.

version (by gravimetry) and the particle size (distribution) using transmission electron microscopy (TEM; Jeol 2000 FX) and dynamic light scattering (Malvern Autosizer IIc) for the polystyrene and poly(vinyl acetate) lattices, respectively.

\section{Emulsion Polymerizations in a Reaction Calorimeter}

Reaction calorimetry was applied to study the effect of emulsification on the rate of heat production during emulsion polymerization of styrene and vinyl acetate. A commercially available reaction calorimeter (RC1e, HP60 reactor, MettlerToledo GmbH, Switzerland) was used for this purpose, whose dimensions and impellers are given in Tables I-III. A detailed description of the characteristics and possibilities of this piece of equipment has been given by Varela de la Rosa et al. ${ }^{13}$ and Sáenz de Buruaga et al. ${ }^{14}$ The configuration of the reaction calorimeter is slightly different from common polymerization reactors. 

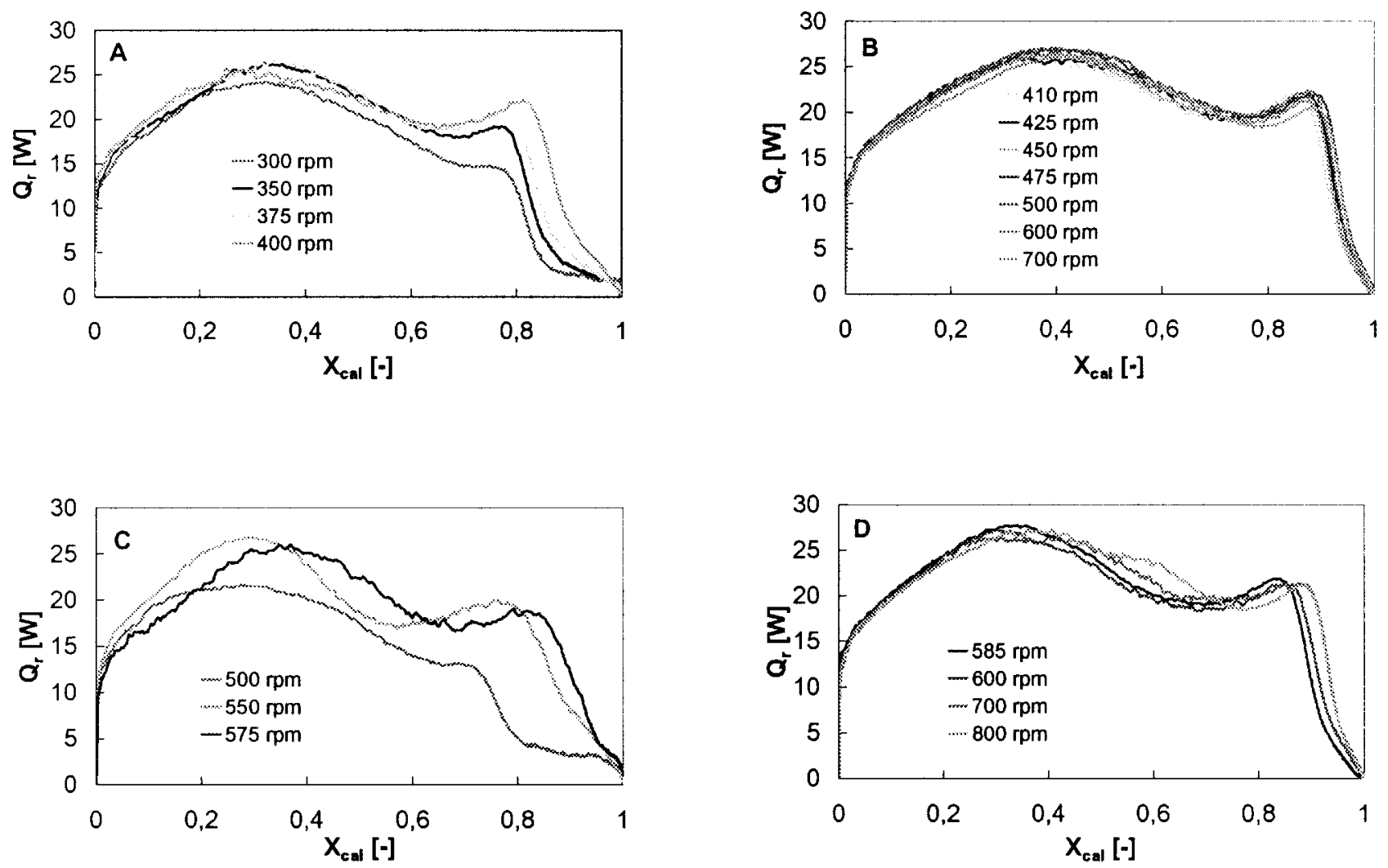

Figure 3 Heat production rate as a function of fractional calorimetric conversion for the emulsion polymerization of styrene: $(\mathbf{A})$ and $(\mathbf{B}) 1 / 3 T ;(\mathbf{C})$ and $(\mathbf{D}) 1 / 3 P ;(\mathbf{A})$ and $(\mathbf{C})$ Poor emulsification; (B) and (D) Sufficient emulsification.

However, during all the experiments the liquid height was always taken equal to the vessel diameter, and the sensors served as baffles. The $\mathrm{RC} 1 \mathrm{e}$ was operated in isothermal mode at a set reactor temperature of $50^{\circ} \mathrm{C}$. Overall heat transfer coefficients were determined by calibrations, in which a given amount of energy was supplied to a nonreacting fluid by an electrical heater over a period of $10 \mathrm{~min}$. If during a calibration the reactor temperature remains constant and no other heat effects occur in the system, the overall heat transfer coefficient follows from eq. (5):

$$
U A \int_{t_{1}}^{t_{2}}\left(T_{r}-T_{a}\right) d t=\int_{t_{1}}^{t_{2}} Q_{c} d t
$$

where $A$ is the heat transfer area, $t_{1}$ and $t_{2}$ are the starting and end times of calibration, $Q_{c}$ is the calibration heat, $T_{r}$ is the reactor temperature, and $T_{a}$ is the corrected jacket temperature. Part of the heat flow from the jacket liquid into the reactor is used to heat or cool the reactor wall and is therefore not transferred into the reactor contents. The corrected jacket temperature, $T_{a}$, calculated from the real jacket temperature, $T_{j}$, com-

Table V Results of Ab-Initio Emulsion Polymerization Experiments of Styrene With a Turbine Impeller 1/3D, Performed in the Reaction Calorimeter

\begin{tabular}{lccc}
\hline $\begin{array}{c}N_{i} \\
{[\mathrm{rpm}]}\end{array}$ & $\begin{array}{c}\Delta_{r} H_{c a l} \\
{[\mathrm{~kJ} / \mathrm{mol}]}\end{array}$ & $\begin{array}{c}d_{p, v \text { final }} \\
{[\mathrm{nm}]}\end{array}$ & $\begin{array}{c}S \\
{[-]}\end{array}$ \\
\hline 300 & 40.5 & 73.7 & 0.183 \\
350 & 60.1 & 75.6 & 0.226 \\
375 & 66.2 & 81.3 & 0.236 \\
400 & 68.6 & 74.6 & 0.240 \\
410 & 69.7 & 78.4 & 0.246 \\
425 & 70.9 & 78.1 & 0.246 \\
450 & 70.7 & 80.6 & 0.243 \\
475 & 69.6 & 78.3 & 0.245 \\
500 & 69.0 & 74.3 & 0.248 \\
600 & 70.1 & 71.3 & 0.244 \\
700 & 68.6 & 73.1 & 0.244 \\
\hline
\end{tabular}


Table VI Results of Ab-Initio Emulsion Polymerization Experiments of Styrene With a Pitched Blade Impeller 1/3D, Performed in the Reaction Calorimeter

\begin{tabular}{cccc}
\hline $\begin{array}{c}N_{i} \\
{[\mathrm{rpm}]}\end{array}$ & $\begin{array}{c}\Delta_{r} H_{c a l} \\
{[\mathrm{~kJ} / \mathrm{mol}]}\end{array}$ & $\begin{array}{c}d_{p, v \text { final }} \\
{[\mathrm{nm}]}\end{array}$ & $\begin{array}{c}S \\
{[-]}\end{array}$ \\
\hline 500 & 37.8 & 67.8 & 0.135 \\
550 & 68.3 & 75.7 & 0.243 \\
575 & 68.5 & 71.0 & 0.245 \\
585 & 70.5 & 75.1 & 0.245 \\
600 & 70.6 & 75.7 & 0.247 \\
700 & 71.1 & 75.2 & 0.246 \\
800 & 69.3 & 75.1 & 0.249 \\
\hline
\end{tabular}

pensates for this effect. Note that the calculation of $U$ according to eq. (5) assumes a perfectly mixed reactor. The overall heat transfer coefficient has been measured in duplicate for each setup. In most cases the deviation in $U$ remains below $1 \%$.

At the beginning and the end of a temperature ramp, the heat capacity of the reactor contents, $C_{p, r}$, can be determined according to eq. (6), provided no other heat effects occur in the system:

$$
U A\left(T_{r}-T_{a}\right)=m_{r} C_{p, r} \frac{d T_{r}}{d t}+m_{i} C_{p, i} \frac{d T_{r}}{d t}
$$

where $m_{i}$ and $C_{p, i}$ are the mass and heat capacity of the inserts (i.e., stirrer, temperature sensor, electrical heater, etc.), respectively; $d T_{r} / d t$ is the heating rate; $m_{r}$ is the mass of reaction mixture.

Once the overall heat transfer coefficient, $U$, and the heat capacity of the reactor contents $C_{p, r}$, are known, the rate of heat production due to reaction, $Q_{r}$, can be determined from the energy balance over the reaction calorimeter. During emulsion polymerization experiments in a reaction calorimeter operated at isothermal mode, the measured $Q_{r}$ provides access to the rate of polymerization, $R_{p}$ :

$$
Q_{r}=R_{p}\left(-\Delta_{r} H_{T}^{*}\right) V_{w}
$$

where $\Delta_{r} H_{T}{ }^{*}$ is the heat of polymerization at temperature $T$ and $V_{w}$ is the volume of the water phase. The calorimetric conversion, $X_{\text {cal }}$, is defined as

$$
X_{\text {cal }}=\frac{\int_{0}^{t} Q_{r} d t}{\int_{0}^{t_{F}} Q_{r} d t}
$$

Table VII $\mathbf{N}_{\text {vis }}^{*}$ for Vinyl Acetate Emulsion Systems Determined With Visualization Experiments on 1.85 and $7.48 \mathrm{dm}^{3}$ scale

\begin{tabular}{lllllllll}
\hline $\begin{array}{c}\text { Impeller } \\
\text { Type }\end{array}$ & $\begin{array}{c}\text { Scale } \\
{\left[\mathrm{dm}^{3}\right]}\end{array}$ & $\begin{array}{c}C_{E} \\
{\left[\mathrm{kmol} / m_{w}^{3}\right]}\end{array}$ & $\begin{array}{c}T_{r} \\
{\left[{ }^{\circ} \mathrm{C}\right]}\end{array}$ & $\begin{array}{c}M \\
{[-]}\end{array}$ & $\begin{array}{c}N_{\text {vis }}^{*} \\
{[\mathrm{rpm}]}\end{array}$ & $\begin{array}{c}T_{q} \\
{[\mathrm{Nm}]}\end{array}$ & $\begin{array}{c}\varepsilon_{a v, \text { torque }} \\
{[\mathrm{W} / \mathrm{kg}]}\end{array}$ & $\begin{array}{c}\varepsilon_{a v, \text { power }} \\
{[\mathrm{W} / \mathrm{kg}]}\end{array}$ \\
\hline $1 / 3 \mathrm{~T}$ & 1.85 & 0 & 20.0 & 0.25 & 381 & 0.013 & 0.27 & 0.12 \\
$1 / 3 \mathrm{~T}$ & 1.85 & 0.01 & 20.0 & 0.25 & 250 & 0.011 & 0.16 & 0.034 \\
$1 / 2 \mathrm{~T}$ & 1.85 & 0.01 & 20.0 & 0.25 & 100 & 0.0095 & 0.054 & 0.016 \\
$1 / 3 \mathrm{P}$ & 1.85 & 0.01 & 20.0 & 0.25 & 400 & 0.0083 & 0.19 & 0.070 \\
$1 / 2 \mathrm{P}$ & 1.85 & 0.01 & 20.0 & 0.25 & 130 & 0.0035 & 0.026 & 0.015 \\
$1 / 3 \mathrm{~T}$ & 7.48 & 0 & 20.0 & 0.25 & 217 & 0.030 & 0.086 & 0.047 \\
$1 / 3 \mathrm{~T}$ & 7.48 & 0 & 50.0 & 0.25 & 236 & 0.024 & 0.073 & 0.069 \\
$1 / 3 \mathrm{~T}$ & 7.48 & 0.01 & 20.0 & 0.25 & 131 & 0.013 & 0.023 & 0.010 \\
$1 / 3 \mathrm{~T}$ & 7.48 & 0.01 & 50.0 & 0.25 & 140 & 0.013 & 0.023 & 0.013 \\
$1 / 3 \mathrm{~T}$ & 7.48 & 0.08 & 20.0 & 0.50 & 163 & 0.013 & 0.027 & 0.020 \\
$1 / 3 \mathrm{~T}$ & 7.48 & 0.08 & 50.0 & 0.50 & 190 & 0.016 & 0.041 & 0.032 \\
$1 / 2 \mathrm{~T}$ & 7.48 & 0.01 & 20.0 & 0.25 & 63 & 0.015 & 0.013 & 0.0085 \\
$1 / 2 \mathrm{~T}$ & 7.48 & 0.01 & 50.0 & 0.25 & 82 & 0.022 & 0.024 & 0.019 \\
$1 / 3 \mathrm{P}$ & 7.48 & 0 & 20.0 & 0.25 & 273 & 0.015 & 0.053 & 0.034 \\
$1 / 3 \mathrm{P}$ & 7.48 & 0 & 50.0 & 0.25 & 356 & 0.018 & 0.086 & 0.075 \\
$1 / 3 \mathrm{P}$ & 7.48 & 0.01 & 20.0 & 0.25 & 273 & 0.014 & 0.053 & 0.042 \\
$1 / 3 \mathrm{P}$ & 7.48 & 0.01 & 50.0 & 0.25 & 292 & 0.015 & 0.053 & 0.034 \\
$1 / 2 \mathrm{P}$ & 7.48 & 0.01 & 20.0 & 0.25 & 95 & 0.015 & 0.018 & 0.0086 \\
$1 / 2 \mathrm{P}$ & 7.48 & 0.01 & 50.0 & 0.25 & 100 & 0.0074 & 0.0096 & 0.010 \\
\hline & & & & & & & &
\end{tabular}


Table VIII Characteristics of the Ab-Initio Emulsion Polymerization Experiments of Vinyl Acetate

\begin{tabular}{|c|c|c|c|c|c|c|c|}
\hline $\begin{array}{l}\text { Impeller } \\
\text { Type }\end{array}$ & $\begin{array}{l}\text { Scale } \\
{\left[\mathrm{dm}^{3}\right]}\end{array}$ & $\begin{array}{c}N_{i} \\
{[\mathrm{rpm}]}\end{array}$ & $\begin{array}{c}T_{r} \\
{\left[{ }^{\circ} \mathrm{C}\right]}\end{array}$ & $\begin{array}{c}\varepsilon_{a v, \text { power }} \\
{[\mathrm{W} / \mathrm{kg}]}\end{array}$ & $\begin{array}{c}X_{\text {final }} \\
{[-]}\end{array}$ & $\begin{array}{c}d_{p, \mathrm{DLS}} \\
{[\mathrm{nm}]}\end{array}$ & Emulsification \\
\hline $1 / 3 \mathrm{~T}$ & 1.85 & 175 & 50.0 & 0.012 & 0.54 & 57 & insufficient \\
\hline $1 / 3 \mathrm{~T}$ & 1.85 & 225 & 50.0 & 0.025 & 0.96 & 102 & insufficient \\
\hline $1 / 3 \mathrm{~T}$ & 1.85 & 240 & 50.0 & 0.030 & 0.98 & 106 & insufficient \\
\hline $1 / 3 \mathrm{~T}$ & 1.85 & 280 & 50.0 & 0.048 & 0.97 & 107 & insufficient \\
\hline $1 / 3 \mathrm{~T}$ & 1.85 & 300 & 50.0 & 0.059 & 0.99 & 107 & good \\
\hline $1 / 3 \mathrm{~T}$ & 1.85 & 415 & 50.0 & 0.16 & 0.97 & 112 & good \\
\hline $1 / 3 \mathrm{~T}$ & 1.85 & 500 & 50.0 & 0.27 & 0.97 & 114 & good \\
\hline $1 / 3 \mathrm{~T}^{*}$ & 1.85 & $300 / 225$ & 50.0 & $0.059 / 0.025$ & 1.0 & 105 & good \\
\hline $1 / 3 \mathrm{P}$ & 1.85 & 300 & 50.0 & 0.029 & 0.58 & 61 & insufficient \\
\hline $1 / 3 \mathrm{P}$ & 1.85 & 425 & 50.0 & 0.084 & 1.0 & 101 & $N_{\mathrm{pol}}^{*}$ \\
\hline $1 / 3 \mathrm{P}$ & 1.85 & 460 & 50.0 & 0.11 & 0.97 & 100 & good \\
\hline $1 / 3 \mathrm{P}$ & 1.85 & 500 & 50.0 & 0.14 & 0.99 & 110 & good \\
\hline $1 / 3 \mathrm{~T}$ & 7.48 & 100 & 50.0 & 0.0046 & 0.56 & 56 & insufficient \\
\hline $1 / 3 \mathrm{~T}$ & 7.48 & 150 & 50.0 & 0.016 & 1.0 & 104 & good \\
\hline $1 / 3 \mathrm{~T}$ & 7.48 & 300 & 50.0 & 0.12 & 0.94 & 107 & good \\
\hline
\end{tabular}

*Pre-Mix Experiment.

where $t_{F}$ is the time at the end of the polymerization. The total heat produced during the reaction time, $t$, can be equated as follows:

$$
\int_{0}^{t} Q_{r} d t=\frac{m_{M, 0} X_{c a l}\left(-\Delta_{r} H_{c a l}\right)}{M_{w t}}=\frac{m_{M, 0} X\left(-\Delta_{r} H_{T}^{*}\right)}{M_{w t}}
$$

where $m_{M, 0}$ is the amount of monomer at the start of the reaction, $\mathrm{M}_{\mathrm{wt}}$ is the molecular weight of the monomer, and $X$ is the gravimetrical conversion.

An experiment in the reaction calorimeter provides $X_{\text {cal }}$ and $\Delta_{r} H_{\text {cal }}$ [eqs. (8) and (9)]. For polymerizations proceeding to complete conversion, $X$ $=X_{\text {cal }}$ and $\Delta_{r} H_{T}=\Delta_{r} H_{\text {cal }}$. In addition to $X_{\text {cal }}$ and $\Delta_{r} H_{\text {cal }}$, the final particle size, $d_{p, v}$ final and the final solids content, $S$, have also been measured.

\section{RESULTS AND DISCUSSION}

Initially, two methods for droplet-size measurement in emulsion systems were applied: off-line laser diffraction spectrometry using a Malvern 2600HSL particle sizer ${ }^{15}$ and an on-line laser back-scattering technique using a Partec 100 apparatus. ${ }^{16}$ Both methods have shown limitations for the investigation of emulsification. ${ }^{1}$ As the measurement of a critical droplet size only results in a certain arbitrarily defined number, we have chosen to use the visual observation of sufficient emulsification based on $N_{\text {vis }}^{*}$ throughout.

\section{Emulsification in Styrene-Water Mixtures}

Visualization and polymerization experiments have been performed on both a 1.85- and a 7.48$\mathrm{dm}^{3}$ scale, for which the results were reported in a previous article. ${ }^{1}$

\section{Emulsion Polymerizations in a Reaction Calorimeter}

Figure 2(a) shows some examples of the time evolution of the heat of reaction, $Q_{r}$. In Figure 2(b) the corresponding fractional calorimetric conversion as a function of time is given. From the data presented in Figure 2, the rate of heat production by reaction can be obtained as a function of the calorimetric conversion (Fig. 3). For experiments with the intrinsic polymerization rate, the shape of the heat of reaction curve is similar. The following explanation can be given for the shape of the curves depicting the rate of heat production by reaction as a function of the fractional calorimetric conversion. According to Varela de la Rosa et al., ${ }^{13}$ the nucleation period is indicated by an increase in the rate of polymerization up to the maximum. Accordingly, our results show a relatively long nucleation period, which is in agreement with the results obtained by Varela de la 

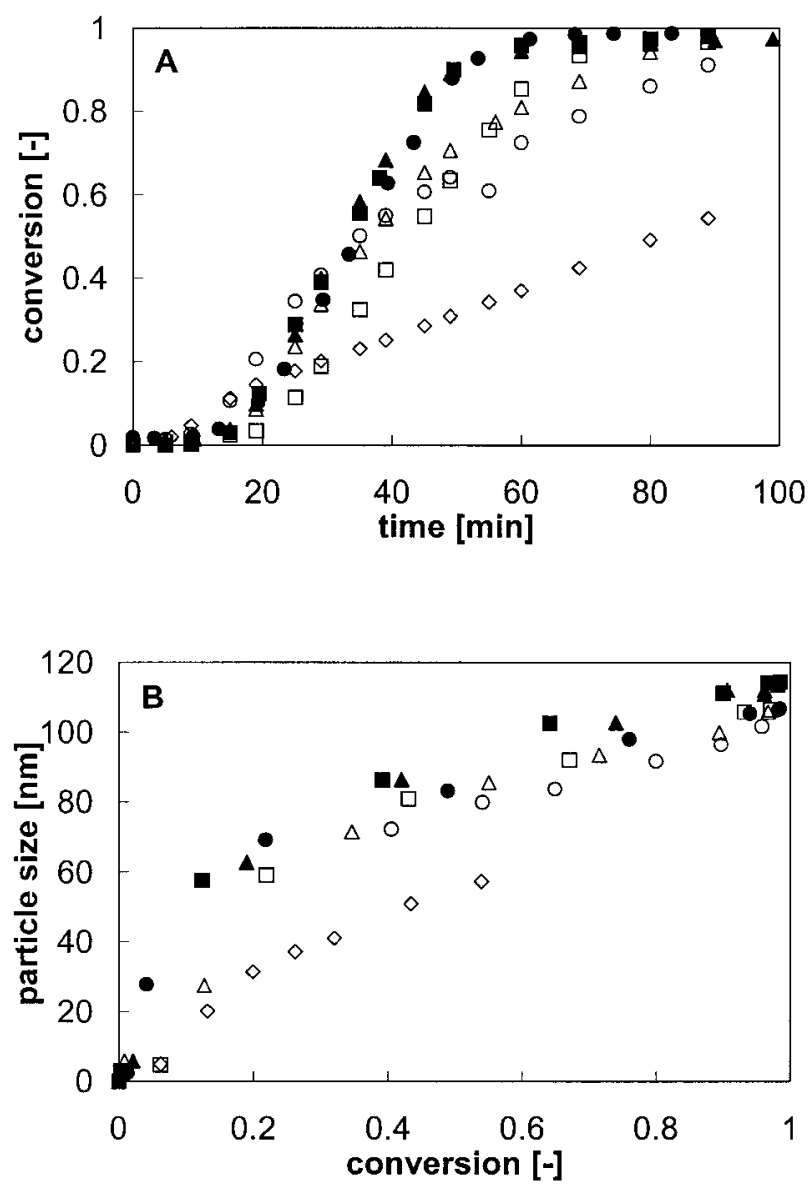

Figure $4 A b$ initio emulsion polymerization experiments of vinyl acetate with a turbine impeller $1 / 3 D$ in diameter on a $1.85-\mathrm{dm}^{3}$ scale: (A) Conversion time history; (B) Particle size versus conversion. Stirrer speed

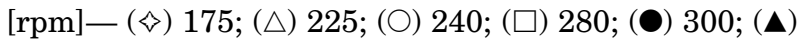
415; (ם) $500\left(N_{\text {vis }}^{*}=250 \mathrm{rpm}, T=20^{\circ} \mathrm{C}\right)$.

Rosa et al. ${ }^{13}$ In regard to the scale of the $y$ axis in Figure $3(\mathrm{~b}, \mathrm{~d})$, the reaction rate can be assumed to be almost constant from $0.25<X_{\text {cal }}<0.45$, which indicates the second interval of the emulsion polymerization. The decrease in the rate of polymerization results from the disappearance of the monomer droplets and the reduction of monomer concentration in the polymer particles. The second maximum in the reaction rate may be caused by the gel effect. ${ }^{13}$

The results of the experiments with the turbine and pitched-blade impellers, both with a diameter one-third of the vessel diameter $(1 / 3 D)$, are summarized in Tables V and VI and shown in Figures 2 and 3 . The distinction between insufficient and proper emulsification is quite precise. In addition to visualization experiments and common emulsion polymerization, reaction calorimetry can ac- curately determine the required process conditions for sufficient emulsification. The results shown in Tables V and VI, as well as in Figures 2 and 3 , indicate that the $N_{\text {pol }}^{*}$ for the turbine impeller is between 400 and $410 \mathrm{rpm}$, while the $N_{\text {pol }}^{*}$ is between 575 and $585 \mathrm{rpm}$ for the pitched-blade impeller.

\section{Emulsification in Vinyl Acetate-Water Mixtures}

Also investigated in addition to the study of emulsification effects in styrene-water mixtures, was the emulsification of vinyl acetate, a monomer that's more water soluble.
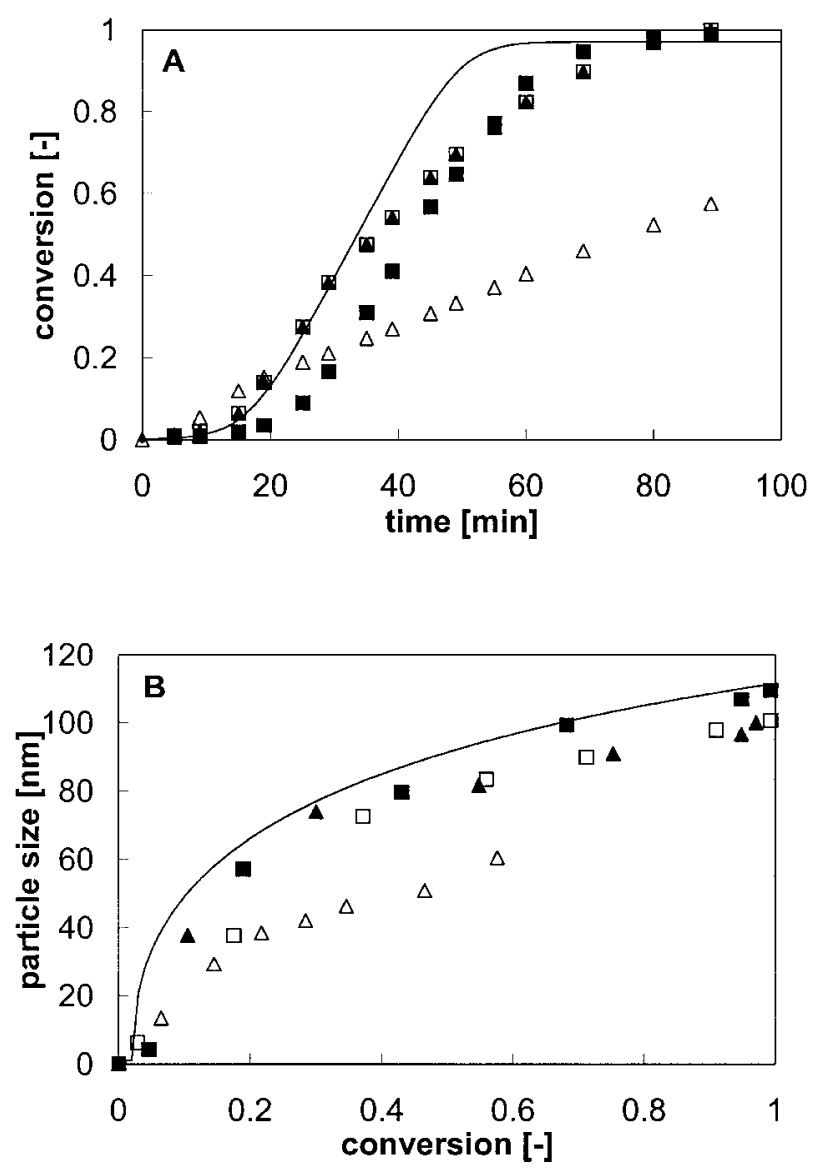

Figure 5 Ab initio emulsion polymerization experiments of vinyl acetate with a pitched-blade impeller $1 / 3 D$ in diameter on a $1.85-\mathrm{dm}^{3}$ scale: (A) Conversion time history; (B) Particle size versus time. Stirrer speed $[\mathrm{rpm}]-(\triangle)$ 300; ( $\square) 425 ;(\mathbf{\Delta}) 460 ;(\boldsymbol{\square}) 500\left(N_{\mathrm{vis}}^{*}\right.$ $\left.=400 \mathrm{rpm}, T=20^{\circ} \mathrm{C}\right) ;$ - : curve fit of polymerization experiments with turbine impeller of $1 / 3 D$ in diameter with impeller speeds of 300,415 , and $500 \mathrm{rpm}$ on a $1.85-\mathrm{dm}^{3}$ scale (Fig. 4). 

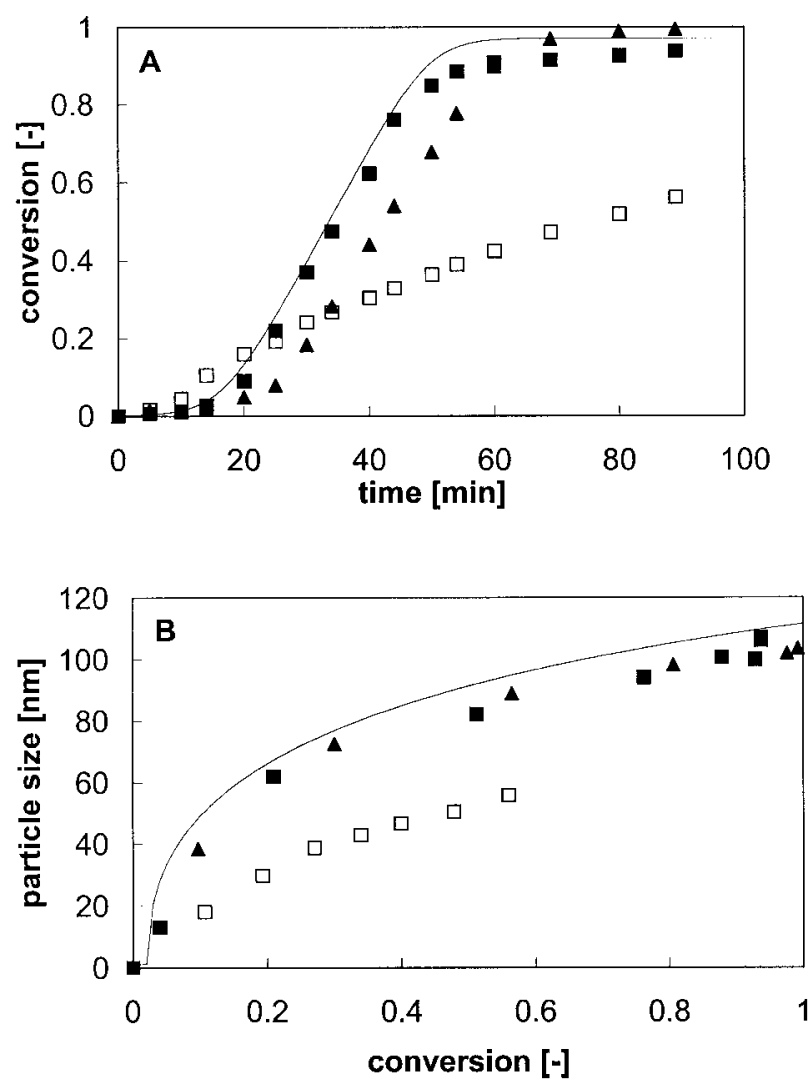

Figure 6 Ab initio emulsion polymerization experiments of vinyl acetate with a turbine impeller $1 / 3 D$ in diameter on a $7.48-\mathrm{dm}^{3}$ scale: (A) Conversion time history; (B) Particle size versus time. Stirrer speed

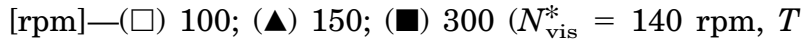
$=50^{\circ} \mathrm{C}$ ); - : curve fit of polymerization experiments with turbine impeller of $1 / 3 D$ in diameter with impeller speeds of 300,415 , and $500 \mathrm{rpm}$ on a $1.85-\mathrm{dm}^{3}$ scale (Fig. 4).

\section{Visualization Experiments for Studying Emulsification}

The stirrer speeds, $N_{\text {vis }}^{*}$, for vinyl acetate-water mixtures as determined by visualization experiments on 1.85 - and $7.48-\mathrm{dm}^{3}$ scales have been collected in Table VII. Our results, in agreement with Fontenot and Schork, ${ }^{3}$ show that proper emulsification of vinyl acetate-water mixtures requires a lower $N_{\text {vis }}^{*}$ and consequently less power input per unit of mass than do styrene-water mixtures under the same circumstances. This is a result of the difference in physicochemical properties, in which the density of the dispersed phase plays a major role. The results obtained for the vinyl acetate-water mixtures on the effects of temperature and emulsifier are similar to the results obtained for the styrene-water emulsions, as reported earlier. ${ }^{1}$ The addition of emulsifier significantly lowers the $N_{\text {vis. }}^{*}$ A higher temperature $\left(50^{\circ} \mathrm{C}\right.$ in stead of $\left.20^{\circ} \mathrm{C}\right)$ results in a larger value of $N_{\text {vis }}^{*}$ because of a higher interfacial tension. Increasing the monomer weight fraction in vinyl acetate-water emulsions leads to a slight increase in $N_{\text {vis. }}^{*}$. As to the influence of impeller type, our results, in agreement with Johansson and Godfrey, ${ }^{17}$ show that a turbine impeller with a diameter of $1 / 3 D$ requires less power than a pitched-blade impeller with the same ratio of impeller diameter to vessel diameter. However, for the larger impeller diameters the influence of impeller type declines. It should be noted that the torque on the impeller shaft determined on a $1.85-\mathrm{dm}^{3}$ scale has a limited accuracy, a result of the low absolute value of the torque for low-viscosity mixtures. Consequently, the differences between "torque"-based and "power number"-based mean-energy dissipation for the $1.85-\mathrm{dm}^{3}$ scale are significantly larger than the corresponding differences for the $7.48-\mathrm{dm}^{3}$ scale because of the better accuracy of the torque measurement on the larger scale.

\section{Emulsion Polymerizations in Common Stirred-Tank Reactors}

Several $a b$ initio emulsion polymerizations of vinyl acetate were performed (Table VIII and Figures 4-6. These experiments also show a significant influence of stirrer speed on the polymerization of styrene. Again, there is a critical stirrer speed required to obtain the intrinsic polymerization rate, which corresponds with the formation of

Table IX Results of Ab-Initio Emulsion Polymerization Experiments of Vinyl Acetate With a Turbine Impeller 1/3D, Performed in the Reaction Calorimeter

\begin{tabular}{lccc}
\hline $\begin{array}{c}N_{i} \\
{[\mathrm{rpm}]}\end{array}$ & $\begin{array}{c}\Delta_{r} H_{c a l} \\
{[\mathrm{~kJ} / \mathrm{mol}]}\end{array}$ & $\begin{array}{c}d_{p, v \text { final }} \\
{[\mathrm{nm}]}\end{array}$ & $\begin{array}{c}S \\
{[-]}\end{array}$ \\
\hline 100 & 11.5 & 86.2 & 0.0902 \\
200 & - & 83.0 & 0.247 \\
300 & 91.4 & 96.2 & 0.249 \\
400 & 93.9 & 101.6 & 0.250 \\
410 & 94.3 & 109.4 & 0.250 \\
425 & 96.0 & 103.0 & 0.249 \\
450 & 95.1 & 107.0 & 0.249 \\
500 & 95.6 & 100.2 & 0.250 \\
600 & 96.6 & 106.1 & 0.250 \\
700 & 95.4 & 104.6 & 0.247 \\
\hline
\end{tabular}


Table X Results of Ab-Initio Emulsion Polymerization Experiments of Vinyl Acetate With a Turbine Impeller 1/2D, Performed in the Reaction Calorimeter

\begin{tabular}{lccc}
\hline $\begin{array}{c}N_{i} \\
{[\mathrm{rpm}]}\end{array}$ & $\begin{array}{c}\Delta_{r} H_{c a l} \\
{[\mathrm{~kJ} / \mathrm{mol}]}\end{array}$ & $\begin{array}{c}d_{p, v \text { final }} \\
{[\mathrm{nm}]}\end{array}$ & $\begin{array}{c}S \\
{[-]}\end{array}$ \\
\hline 100 & 86.3 & 77.3 & 0.250 \\
125 & 94.5 & 96.3 & 0.250 \\
130 & 94.3 & 97.0 & 0.250 \\
135 & 95.8 & 92.6 & 0.250 \\
142 & 96.2 & 96.7 & 0.250 \\
150 & 94.0 & 99.2 & 0.245 \\
200 & 94.2 & 101.4 & 0.247 \\
300 & 90.8 & 102.5 & 0.248 \\
\hline
\end{tabular}

larger particles in the latex product. For experiments with insufficient emulsification, the rate of mass transfer from the monomer phase to the growing polymer particles is low as a result of the small interfacial area. The course of the reaction and the particle size development are approximately the same for all the polymerization experiments with sufficient emulsification, except for some experiments with the pitched-blade impeller, which show a slight difference in conversion time history. This is probably because of some inhibition effects. Figures 4 and 5 show that the $N_{\mathrm{pol}}^{*}$ on the $1.85-\mathrm{dm}^{3}$ scale is approximately 290 $\mathrm{rpm}$ and $425 \mathrm{rpm}$ for the turbine and pitchedblade impeller, respectively. According to Figure $6, N_{\text {pol }}^{*}$ on the $7.48-\mathrm{dm}^{3}$ scale lies between $100 \mathrm{rpm}$ and $150 \mathrm{rpm}$ for the turbine impeller. In all cases, the visually determined $N_{\text {vis }}^{*}$ agrees reasonably well with $N_{\text {pol }}^{*}$ (Table VII). Note that on the 1.85$\mathrm{dm}^{3}$ scale $N_{\text {vis }}^{*}$ has been determined at a lower

Table XI Results of Ab-Initio Emulsion Polymerization Experiments of Vinyl Acetate With a Pitched Blade Impeller 1/3D, Performed in the Reaction Calorimeter

\begin{tabular}{lccc}
\hline $\begin{array}{c}N_{i} \\
{[\mathrm{rpm}]}\end{array}$ & $\begin{array}{c}\Delta_{r} H_{c a l} \\
{[\mathrm{~kJ} / \mathrm{mol}]}\end{array}$ & $\begin{array}{c}d_{p, v \text { final }} \\
{[\mathrm{nm}]}\end{array}$ & $\begin{array}{c}S \\
{[-]}\end{array}$ \\
\hline 300 & 85.3 & 85.8 & 0.250 \\
400 & 93.9 & 101.5 & 0.250 \\
410 & 94.4 & 104.6 & 0.250 \\
425 & 95.3 & 107.6 & 0.250 \\
450 & 94.3 & 101.9 & 0.250 \\
500 & 95.4 & 101.8 & 0.250 \\
600 & 94.7 & 104.1 & 0.250 \\
700 & 94.6 & 106.7 & 0.248 \\
\hline
\end{tabular}

Table XII Results of Ab-Initio Emulsion Polymerization Experiments of Vinyl Acetate With a Pitched Blade Impeller 1/2D, Performed in the Reaction Calorimeter

\begin{tabular}{lccc}
\hline $\begin{array}{c}N_{i} \\
{[\mathrm{rpm}]}\end{array}$ & $\begin{array}{c}\Delta_{r} H_{c a l} \\
{[\mathrm{~kJ} / \mathrm{mol}]}\end{array}$ & $\begin{array}{c}d_{p, v \text { final }} \\
{[\mathrm{nm}]}\end{array}$ & $\begin{array}{c}S \\
{[-]}\end{array}$ \\
\hline 100 & 84.6 & 72.0 & 0.246 \\
125 & - & 97.8 & 0.248 \\
135 & 92.6 & 90.3 & 0.250 \\
142 & 93.8 & 96.1 & 0.249 \\
150 & 93.6 & 98.0 & 0.250 \\
160 & 95.4 & 99.2 & 0.250 \\
175 & 95.3 & 99.3 & 0.249 \\
200 & 94.2 & 99.5 & 0.249 \\
\hline
\end{tabular}

temperature than $N_{\text {pol. }}^{*}$. Consequently, $N_{\text {pol }}^{*}$ is underestimated using the visualization results.

\section{Emulsion Polymerizations in a Reaction Calorimeter}

The results of the reaction calorimetric study on emulsification effects during emulsion polymerization of vinyl acetate are collected in Tables IX-XII and Figure 7. In Table XIII the values of $N_{\text {pol }}^{*}$ as obtained with the RC1e equipment are summarized for the different impellers used. Corresponding to the reaction calorimetric experiments of styrene, the results of the emulsion polymerization of vinyl acetate show that $N_{\text {pol }}^{*}$ can accurately be determined with reaction calorimetry. The results in Table XIII point to a minor effect of the impeller type on $N_{\mathrm{pol}}^{*}$. However, larger impeller-to-vessel ratios lead to considerably lower values of $N_{\mathrm{pol}}^{*}$.

\section{Premix Experiments}

Visualization experiments have shown that vinyl acetate-water emulsions exhibit relatively long stability after the stirrer has been stopped. Assuming good emulsion stability over a sufficiently long period of time, it may be convenient to premix an emulsion polymerization reaction mixture at a rather high impeller speed and perform the reaction with a lower stirrer speed. The impeller speed should then be lowered just before initiator addition (Fig. 8). In principle the use of a premixer reduces the overall energy consumption. ${ }^{18}$ An additional advantage of a separate premix setup for emulsification is the possibility of equipping the polymerization tank with an impeller designed for proper mixing of reaction mixtures 

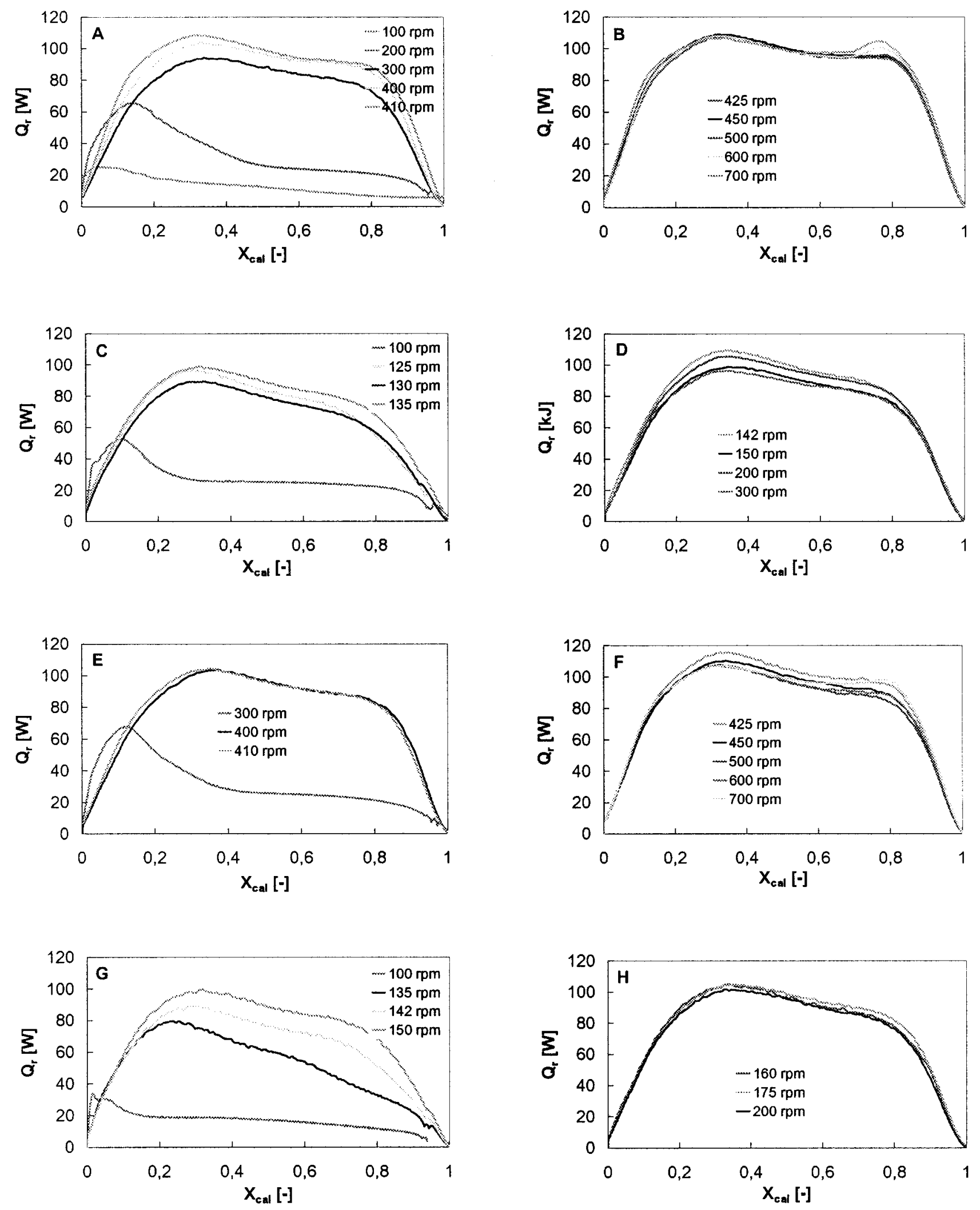

Figure 7 Heat production rate as a function of fractional calorimetric conversion for the emulsion polymerization of vinyl acetate: $(\mathbf{A})$ and $(\mathbf{B}) 1 / 3 T ;(\mathbf{C})$ and $(\mathbf{D}) 1 / 2 T ;(\mathbf{E})$ and $(\mathbf{F}) 1 / 3 P ;(\mathbf{G})$ and $(\mathbf{H}) 1 / 2 P ;(\mathbf{A}),(\mathbf{C}),(\mathbf{E})$, and $(\mathbf{F})$ Poor emulsification; $(\mathbf{B}),(\mathbf{D}),(\mathbf{F})$, and $(\mathbf{H})$ Sufficient emulsification. 
Table XIII $\mathbf{N}_{\text {pol }}^{*}$ for Vinyl Acetate Emulsion Polymerization as Determined from Reaction Calorimetic Studies

\begin{tabular}{lc}
\hline Impeller Type & $N_{\text {pol }}^{*}[\mathrm{rpm}]$ \\
\hline $1 / 3 \mathrm{~T}$ & $410-425$ \\
$1 / 2 \mathrm{~T}$ & $135-142$ \\
$1 / 3 \mathrm{P}$ & $410-425$ \\
$1 / 2 \mathrm{P}$ & $150-160$ \\
\hline
\end{tabular}

with a high volume fraction of particles. Such so-called high-solid-reaction mixtures often show pseudo-plastic rheological behavior. ${ }^{19}$ Proper impeller design for these kinds of fluids can avoid stagnant low-shear zones. Additionally, heat transfer can be improved as compared to heat transfer in vessels equipped with a turbine or a pitched-blade impeller in which stagnant zones are probable. ${ }^{19}$

Figures 9 and 10 show, respectively, the results of the premix emulsion polymerization on a 1.85$\mathrm{dm}^{3}$ scale and the results obtained with the reaction calorimeter. These results indicate that the polymerization of vinyl acetate can be performed at $N_{i}<N_{\text {pol }}^{*}$ by premixing the reaction mixture at $N_{i}>N_{\text {pol }}^{*}$. The vinyl acetate-water emulsion remains relatively stable during polymerization, which guarantees the intrinsic polymerization rate.

\section{CONCLUSIONS}

The results of this study on emulsification in batch-emulsion polymerization of styrene and vinyl acetate show that the lowest impeller speed for sufficient emulsification, $N_{\text {vis }}^{*}$, as determined

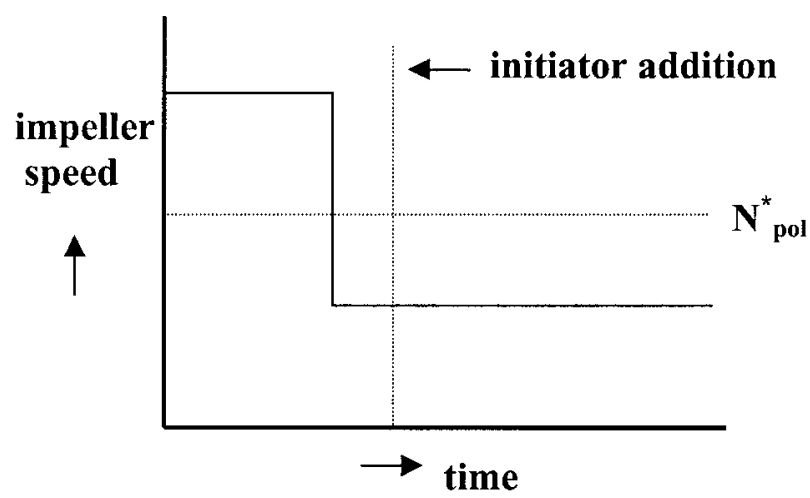

Figure 8 Schematic time schedule of a premix experiment for the emulsion polymerization of vinyl acetate.
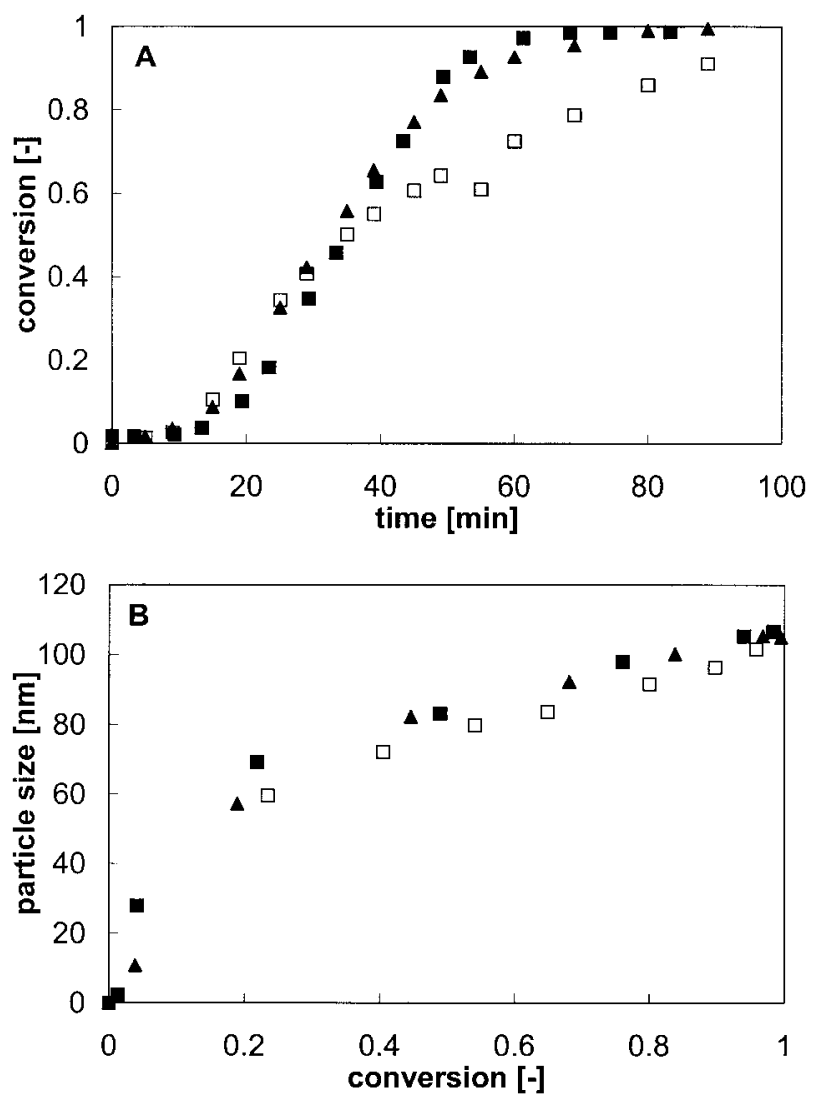

Figure $9 \quad A b$ initio emulsion polymerization experiments of vinyl acetate with a turbine impeller $1 / 3 D$ in diameter on a $1.85-\mathrm{dm}^{3}$ scale: (A) Conversion time history; (B) Particle size versus time. Stirrer speed [rpm]—( $\square$ ) 225; ( $\Delta$ ) 300/225 (premix experiment); $300\left(N_{\text {pol }}^{*}=290 \mathrm{rpm}\right)$.

by a visual criterion, in most cases corresponds with the impeller speed above which intrinsic polymerization occurs, $N_{\text {pol }}^{*}$. The required process

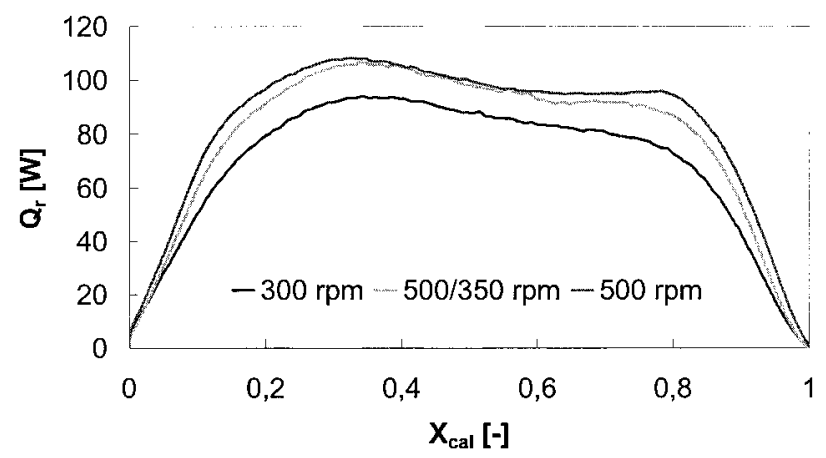

Figure 10 Rate of heat production as a function of fractional calorimetric conversion for the emulsion polymerization of vinyl acetate with a turbine impeller $1 / 3 D$ in diameter, performed in the reaction calorimeter $\left(N_{\text {pol }}^{*}=420 \mathrm{rpm}\right)$. 
conditions for sufficient emulsification can accurately be determined with visualization experiments for studying emulsification in combination with polymerization experiments both in a common stirred-tank reactor and in a reaction calorimeter.

Our results show that dispersion with a turbine impeller requires less power per unit of mass to obtain sufficient emulsification as compared to a pitched-blade impeller, except for the larger impeller diameter used in the case of vinyl acetate-water mixtures. This is in agreement with the observations of Johansson and Godfrey. ${ }^{17}$ In general, a larger impeller diameter requires less power per unit of mass for proper emulsification.

Concerning the influence of physicochemical properties of the mixture on emulsification, the addition of emulsifier to the mixture considerably reduces the required stirrer speed for sufficient emulsification. At elevated temperatures the coalescence rate of the monomer droplets is higher, and consequently the critical impeller speed for sufficient emulsification increases. Our results, in agreement with Fontenot and Schork, ${ }^{3}$ show that the emulsification of styrene-water mixtures requires more power input for sufficient emulsification as compared to vinyl acetate-water mixtures. Because of the relatively good emulsion stability of vinyl acetate-water mixtures over a sufficiently long period of time, it is in principle possible to premix the mixture at a high stirrer speed and perform the emulsion polymerization at a lower stirrer speed.

The authors wish to thank the Foundation of Emulsion Polymerization (SEP) for the financial support of this study and M. P. M. Kuppens and H. M. A. M. Woestenberg for their contributions to this work.

\section{NOMENCLATURE}

$1 / 2 P \quad 45^{\circ}$ pitched six-bladed impeller with $d$ $=1 / 2 D$

$1 / 2 T \quad$ Rushton turbine impeller with $d=1 / 2 D$

$1 / 3 P \quad 45^{\circ}$ pitched six-bladed impeller with $d$ $=1 / 3 D$

$1 / 3 T \quad$ Rushton turbine impeller with $d=1 / 3 D$

A heat transfer area $\left(\mathrm{m}^{2}\right)$

$C \quad$ clearance of impeller from tank bottom (m)

$C_{B} \quad$ buffer concentration $\left(\mathrm{kmol} / m_{w}{ }^{3}\right)$

$C_{E} \quad$ overall emulsifier concentration (kmol/ $\left.m_{w}{ }^{3}\right)$

\begin{tabular}{|c|c|}
\hline$C_{I}$ & initiator concentration $\left(\mathrm{kmol} / m_{w}^{3}\right)$ \\
\hline$C_{p, i}$ & $\begin{array}{l}\text { specific heat capacity of inserts in reac- } \\
\quad \text { tor }\left(\mathrm{J} \mathrm{kg}^{-1} \mathrm{~K}^{-1}\right)\end{array}$ \\
\hline$C_{p, r}$ & $\begin{array}{l}\text { specific heat capacity of liquid inside } \\
\text { reactor }\left(\mathrm{J} \mathrm{kg}^{-1} \mathrm{~K}^{-1}\right)\end{array}$ \\
\hline$\omega$ & impeller diameter $(\mathrm{m})$ \\
\hline$D$ & internal tank diameter $(\mathrm{m})$ \\
\hline$d_{b}$ & diameter baffles (m) \\
\hline$d_{p, D L S}$ & $\begin{array}{l}\text { particle diameter determined with dy- } \\
\text { namic light scattering }(\mathrm{m})\end{array}$ \\
\hline$d_{p, v \text { final }}$ & final particle size (m) \\
\hline & height of reactor $(\mathrm{m})$ \\
\hline$H_{\text {fill }}$ & height of reactor filled with li \\
\hline & impeller blade length $(\mathrm{m})$ \\
\hline$M$ & monomer weight fraction in recipe $(-)$ \\
\hline$m_{i}$ & mass of inserts in reactor $(\mathrm{kg})$ \\
\hline$m_{M}$ & $\begin{array}{l}\text { amount of monomer at the start of the } \\
\text { polymerization }(\mathrm{kg})\end{array}$ \\
\hline$m_{r}$ & mass of liquid in reactor $(\mathrm{kg})$ \\
\hline$M_{r r}$ & mass of reaction $r$ \\
\hline$M_{w t}$ & $\begin{array}{l}\text { molecular weight of the monomer }(\mathrm{kg} / \\
\mathrm{kmol})\end{array}$ \\
\hline$N$ & number $\left(1 / m_{w}^{3}\right)$ \\
\hline$N^{*}$ & ed for proper emul- \\
\hline$N_{\text {vis }}^{*}$ & $\begin{array}{l}\text { peller speed for proper emul- } \\
\text { on as determined by polymer- } \\
\text { experiments }(1 / \mathrm{s})\end{array}$ \\
\hline$N_{\text {vis }}^{*}$ & $\begin{array}{l}\text { lowest impeller speed for proper emul- } \\
\text { sification as determined by visualiza- } \\
\text { tion experiments }(1 / \mathrm{s})\end{array}$ \\
\hline$N_{i}$ & impeller \\
\hline$N_{P}$ & powel \\
\hline$P$ & nown \\
\hline$Q$ & disc \\
\hline$Q_{c}$ & calib \\
\hline$Q_{r}$ & ction $(\mathrm{W})$ \\
\hline$S$ & final \\
\hline$t$ & \\
\hline$T_{a}$ & ure inside jacket $(\mathrm{K})$ \\
\hline$t_{b}$ & thickness baffles (m) \\
\hline$T_{q}$ & torque $(\mathrm{N} \mathrm{m})$ \\
\hline$T_{r}^{4}$ & temperature il \\
\hline$U$ & $\begin{array}{l}\text { overall heat transfer coefficient }\left(\mathrm{W} \mathrm{m}^{-2}\right. \\
\left.\mathrm{K}^{-1}\right)\end{array}$ \\
\hline$V_{M}$ & volume of reaction mixture $\left(\mathrm{m}^{3}\right)$ \\
\hline$w$ & impeller blade wid \\
\hline$X$ & conv \\
\hline$X_{\text {ca }}$ & calorimetric conversion $(-)$ \\
\hline$X_{\text {fin }}$ & conversion of final latex $(-)$ \\
\hline$\Delta_{r} H$ & $\begin{array}{l}\text { heat of polymerization determined with } \\
\text { reaction calorimetry }(\mathrm{kJ} / \mathrm{mol})\end{array}$ \\
\hline$\Delta_{r} H_{T}^{*}$ & $\begin{array}{l}\text { heat of polymerization at temperature } \\
\quad T(\mathrm{~kJ} / \mathrm{mol})\end{array}$ \\
\hline
\end{tabular}


$\epsilon_{a v \text {,power }}$ mean energy dissipation based on
power number (W/kg)

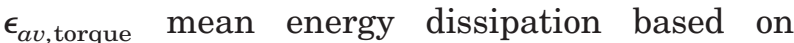
torque measurements $(\mathrm{W} / \mathrm{kg})$

\section{REFERENCES}

1. Kemmere, M. F.; Meuldijk, J.; Drinkenburg, A. A. H.; German, A. L. J Appl Polym Sci 1999, 74, 3225.

2. Becher, P. Emulsions, Theory and Practice, 2nd ed.; Reinhold Publishing Corporation: New York, 1977.

3. Fontenot, K.; Schork, F. J. Ind Eng Chem Res 1993, $32,373$.

4. Smith, W. V.; Ewart, R. H. J Chem Phys 1948, 16(6), 592.

5. Hansen, F. K.; Ugelstad, J. J Polym Sci 1978, 16, 1953.

6. Ugelstad, J.; Mörk, P. C.; Aasen, J. O. J Polym Sci 1967, A-1(5), 2281.

7. Nomura, M. Emulsion Polymerization; Piirma, I., Ed.; Academic Press: New York, 1982.

8. Meuldijk, J.; van Strien, C. J. G.; van Doormalen, F. A. H. C.; Thoenes, D. Chem Eng Sci 1992, 47(911), 2603.

9. Kusters, K. A. Ph.D. Thesis, Eindhoven University of Technology, 1991.
10. Thoenes, D. Chemical Reactor Development, from Laboratory to Industrial Production; Kluwer Academic Publishers: Norwell, MA, 1994.

11. Bates, R. L.; Fondy, P. L.; Corpstein, R. R. Ind Eng Chem Res 1963, 2(4), 310.

12. Kemmere, M. F.; Mayer, M. J. J.; Meuldijk, J.; Drinkenburg, A. A. H.; J Appl Polym Sci 1999, 71, 2419.

13. Varela de Rosa, L.; Sudol, E. D.; El-Aasser, M. S.; Klein, A. J Polym Sci, Part A: Polym Chem 1996 , $34,461$.

14. Sáenz de Buruaga, I.; Echevarrío, A.; Armitage, P. D.; de la Cal, J. C.; Leiza, J. R.; Asua, J. M. AIChE J 1997, 43(4), 1069.

15. Hoedemakers, G. F. M. Ph.D. Thesis, Eindhoven University of Technology, 1990.

16. van den Boomen, F. H. A. M; Akhssay, M. Laboratory of Process Development, Eindhoven University of Technology, internal report, 1997.

17. Johansson, A. C.; Godfrey, J. C.; Proc 9th Eur Mixing Conf 1997, 11, 52, 255.

18. Maa, Y. F.; Hsu, C. Microencapsulation 1996, 13, 4, 419.

19. Kemmere, M. F.; Meuldijk, J.; Drinkenburg, A. A. H.; German, A. L. Polym,. React. Eng 1998, 6(3-4), 243. 